\title{
Cancer, the mind and the person: what we know about the causes of cancer
}

\author{
David W. Kissane \& Yasmin Al-Asady
}

\begin{abstract}
SUMMARY
At a time when patients are challenged to cope adaptively with both the diagnosis and treatment of cancer, clinicians need to respond appropriately to the many inevitable questions about the causes of cancer and contributing factors, including 'Is this my fault?'. The evidence guiding answers to such questions has been confounded by many methodological challenges, but personality, stress and life events are no longer considered causes of cancer. However, social isolation, untreated depression and social deprivation continue to influence quality of life and reduce cancer survival times. Psychiatry might play a role in promoting lifestyle changes that reduce the risk of cancer, but more importantly it can influence disease progression by optimising patients' adaptation to the many challenges that cancer brings.
\end{abstract}

\section{LEARNING OBJECTIVES}

- Be able to explain to patients why stress is no longer accepted as a cause of cancer

- Highlight the importance of social support and guide patients to optimise this as needed

- Convince any oncologists who refer patients with cancer to you about the importance of screening for and recognising depression in their patients

\section{DECLARATION OF INTEREST}

None

Psychiatric disorders are common in oncology and palliative care. Of considerable interest has been their contribution to the onset of cancer, its management, disease progression and mortality. If the clinical goal is to facilitate adaptation and sustain quality of life in the face of oncological illnesses, psychiatrists need to be able to discuss with patients their concerns about the aetiology of cancer and the contribution of lifestyle habits, stress, social support, depression and socioeconomic factors. In this article, we review the evidence that personality, stress, life events and social support are associated with the development of cancer and also review the psychosocial factors associated with cancer progression and mortality. We begin with review of the prevalence of psychiatric disorders in patients with cancer to establish the context in which the psychiatrist might meet such a patient.

\section{Prevalence of psychiatric disorder}

A cancer diagnosis is commonly perceived as dire and threatening. Not surprisingly, comorbid psychiatric disorders are prevalent. Although the now old study by the Psychosocial Collaborative Oncology Group (PSYCOG) in the USA recorded that $89 \%$ of cancer patients with psychiatric disorders had no pre-cancer history of mental illness (Derogatis 1983), not until recent years have epidemiological studies updated our understanding of this morbidity. Vehling et al (2012) applied meta-analytical methods to find an $11 \%$ (95\% CI 8.1-15.1) prevalence of affective disorders and a 10\% (95\% CI 6.9-14.8) prevalence of anxiety disorders from structured psychiatric interviews in oncology, while in palliative care, Mitchell et al (2011) recorded even higher rates of depression, at 16.5\% (95\% CI 13.1-20.3). Structured psychiatric interviews offer more conservative prevalence rates than self-report measures, as in the latter adjustment disorders are more readily misclassified as clinical depression.

A methodologically rigorous epidemiological study from five cancer centres in Germany used a proportionally stratified random sample based on the nationwide incidence of all cancer diagnoses (Mehnert 2012a). With a participation rate of $68 \%, 4200$ patients were initially screened and $2143(53 \%)$ were then randomly assigned and interviewed using the oncology-specific adaptation of the Composite International Diagnostic Interview (CIDI-O). The most common mental disorders were anxiety disorders (4week prevalence: $13.5 \%$, 12-month prevalence: $18.5 \%$ ), followed by affective disorders (4-week prevalence: $8.5 \%$, 12-month prevalence: $15.6 \%$ ) and somatoform disorders (4-week prevalence: 5.6\%, 12-month prevalence: 10.3\%) (Mehnert
ARTICLE

David W. Kissane is Professor of Psychiatry, Head of Discipline and Chairman of the Department of Psychiatry at Monash University, Australia. He is also Adjunct Professor of Psychiatry at Weill Cornell Medical College and at Memorial Sloan Kettering Cancer Center, New York. Yasmin Al-Asady is a first-year core psychiatry trainee (CT1) on the Charing Cross rotation, London. Correspondence Professor D. W. Kissane, Department of Psychiatry, Monash University, Level 3, P Block, Monash Medical Centre, 246 Clayton Road, Clayton, Victoria 3168, Australia. Email: david. kissane@monash.edu 
$2012 b)$. Using self-report measures, $23.9 \%$ of the participants had moderate to severe depression (Patient Health Questionnaire-9, PHQ-9) and $14.2 \%$ had moderate to severe levels of generalised anxiety disorder (Generalised Anxiety Disorder, GAD-7). Of interest, substance use disorders had a 4 -week prevalence of $5.5 \%$ and a 12 -month prevalence of $9.5 \%$, whereas post-traumatic stress disorder (PTSD) was less prominent, with a 4-week prevalence of $2.5 \%$ and a 12 -month prevalence of $3.2 \%$. A recent meta-analysis of 25 studies (4189 participants) of cancer-related PTSD identified 9 studies that used a structured diagnostic interview to reveal a $5.1 \%$ rate of PTSD in advanced disease (Abbey 2015).

These data, both meta-analytical and epidemiological, present targets for service delivery, which will be dependent on appropriate staffing of cancer centres and related psychosocial supportive care programmes. Programmes the world over fall well short of the optimal recognition and treatment of this level of psychiatric disorder. Fresh key performance indicators are thus called for to pursue such targets for care delivery.

Let us turn to factors that patients worry might have been a cause of their cancer.

\section{Personality}

The existence of a 'cancer-prone personality' has been much debated through the decades (e.g. Temoshok 1987). Shaffer's 35-year follow-up of a longitudinal study of medical students who were given Rorschach tests identified that cancer was 15 times more frequent in individuals who were loners, non-aggressive or emotionally repressed (Shaffer 1987). Such interpretations were quite subjective. This sort of study, together with the body of work on alexithymia, had raised support for a cancer-prone personality, dubbed type C (Grossarth-Maticek 1988). However, many of the studies that explored this had methodological difficulties associated with being retrospective and involving older cohorts of patients.

The Danish Cancer Society conducted a cohort study of 1031 individuals, who completed the Eysenck Personality Inventory (EPI) in 1976, alongside their history of smoking, alcohol and related parameters. Extraversion had been postulated to increase the risk of smoking and cancer, but at 20-year follow-up, no significant increase in cancer occurrence was evident (Schapiro 2001). A larger prospective cohort of 59548 Swedish and Finnish twins completed the EPI, among whom 4631 cases of cancer had developed by 30-year follow-up (Nakaya 2010). In multivariate analyses, neither extraversion nor neuroticism were associated with cancer in this study. A recent meta-analysis of eight prospective studies, involving 42000 participants, again failed to find any association between personality traits and cancer incidence or mortality (Jokela 2014).

A particularly problematic outcome from such a construct as the cancer-prone personality is the likelihood that patients will blame themselves and feel guilty for the development of their cancer. Most psycho-oncologists are sceptical about the validity of such a personality type. We do well to remember the history of psychiatry and early descriptors of personality that were proposed to cause illnesses such as tuberculosis, tertiary syphilis or peptic ulcer before the bacteriological aetiology of these diseases was recognised.

\section{Lifestyle habits}

Although the data regarding a cancer-prone personality are questionable, personality traits such as sensation-seeking and impulsivity may predispose to early risky behaviour (Zuckerman 2000). With continued exposure, early behavioural experimentation can develop into maladaptive lifestyle habits such as smoking, alcohol consumption, lack of exercise and obesity, all of which are linked to both cancer incidence and the quality of life of patients with cancer.

\section{Exercise}

Multiple studies have demonstrated that physical activity has a convincing protective role against colon cancer and a probable protective role against breast and endometrial malignancies (Kruk 2013). Physical activity of 30-60 min per day has been shown in epidemiological studies to reduce rates of colon cancer in men and women by $30-40 \%$ and breast cancer in women by $20-30 \%$ compared with inactive people (Lee 2003). Meta-analyses based on 60 studies of exercise prescribed after treatment for breast cancer showed moderate reductions of fatigue and cancer-specific concerns (Speck 2010).

The well-established positive effect of physical activity on mood extends to affective disorders in patients with cancer, as demonstrated by a metaanalysis of 15 randomised controlled trials among cancer survivors which showed a modest reduction in depressive symptoms $(-0.22 ; 95 \% \mathrm{CI}-0.43$ to -0.09), particularly when exercise was performed under supervision (Craft 2011).

Several mechanisms have been proposed to underlie the benefits of physical activity in the context of cancer, including changes in endogenous sexual and metabolic hormone levels, reduction of systemic inflammation and improved immune 
function. Perhaps most significant, however, is the protective effect afforded by decreased central obesity (Friedenreich 2002; Kruk 2013).

\section{Obesity}

Obesity has been consistently shown to increase the risk of developing endometrial cancer, breast cancer in postmenopausal women and renal cell carcinoma (Carroll 1998). It has also been shown to contribute to the progression of precancerous changes into hepatocellular, pancreatic and prostate malignancies (Carroll 1998; Li 2009). Population studies of more than 28000 people (1965-1993) linked to the cancer registry in Sweden revealed a 33\% excess incidence of cancer in obese individuals (Wolk 2001). Proposed underlying mechanisms include inflammatory adipokine activity, insulin resistance and changes in steroid hormone activity (Calle 2004; Redinger 2007). Incidentally, chronic inflammation has also been implicated in the development of depressive disorder (Haroon 2012), which may contribute to the increased risk of depression in obese people as well as depression being found to be predictive of obesity (Luppino 2010).

\section{Smoking}

Smoking is another lifestyle habit that has long been associated with cancer incidence. In comparison to cigarette smoking, the carcinogenic effects of smokeless tobacco use have received little attention. In recent years, however, numerous studies have emerged from the Indian subcontinent highlighting the increased risk of cancer in those who chew paan and gutka (areca nut and betel quid) (Critchley 2003). Similarly, shisha smoking is emerging as a significant global public health problem (Shishani 2012). Although these practices are socially perceived to be less harmful than cigarette smoking, they have been directly linked to both lung and head and neck malignancies (Javed 2010; Maziak 2013). The paucity of data and lack of methodological rigour applied to this area of research needs to be addressed in order to manage the growing global burden of tobaccorelated disease and inform policy regarding the regulation of such substances (Changrani 2005).

Hospital admission can be utilised as a window of opportunity to improve the lifestyle of patients (Box 1). Counselling to quit that is delivered to smokers in association with an admission to hospital has been shown in meta-analyses to be effective (Freund 2009; Parsons 2010). Smoking is three times more prevalent among people with mental illnesses, and smoking cessation is particularly important, given the risks of vascular
BOX 1 The stigma of smoking

John was just 50 when his non-small cell lung cancer was diagnosed. He had smoked since 15 years of age and talked of his sense that relatives and friends thought 'We told you so'. As his cancer was metastatic to bones and brain at diagnosis, his prognosis was fairly grim despite recent advances such as cetuximab. His wife worked, but his two adolescent sons were still completing high school, hoping to go on to university. Loss of the father and his income would be a severe blow for his family. This saddened John and caused him significant embarrassment. He had so intended to be a good provider. He felt deep regret for the many years of excuses he made about his nicotine dependence and his inability to quit smoking. A course of varenicline and some nicotine replacement therapy had assisted his easy withdrawal. Now acceptance of the consequences of his lifestyle choices was a bitter pill. He felt too awkward about his predicament to be able to easily share how he felt about this with his physicians. Facilitating a conversation with his sons about his regret at smoking helped John feel he was both educating and advising them to not make the mistakes of his own youth.

and cardiac disease, alongside cancer. With some eight or more sessions, $20 \%$ of smokers are able to cease (Burkhalter 2005). This outcome is clearly dependent on the stage of motivation of the patient. Motivational counselling alone has limited efficacy ( $d=0.11 ; 95 \%$ CI -0.05 to 0.27 ) (Burke 2003) in helping patients stop smoking, unless supplemented by nicotine replacement therapies $(\mathrm{OR}=2.37$; 95\% CI 1.12-5.13) and medications such as varenicline $(\mathrm{OR}=2.41 ; 95 \%$ CI $1.91-3.12)$ and buproprion $(\mathrm{OR}=2.07 ; 95 \%$ CI $1.73-2.55)$ (Eisenberg 2008). The concept of a 'teachable moment' in a person who is approaching surgery or attending their dentist has been useful in helping to recognise when people may be influenced to stop smoking (McBride 2003). Public health initiatives, including television advertisements that promote awareness of the dangers of tobacco in all forms and of the need to quit, are certainly fundamental and vital for community well-being (Wakefield 2011).

\section{Alcohol and substance misuse}

Alcohol is a well-established risk factor for the development of oropharyngeal, laryngeal and oesophageal cancers, contributing to up to $80 \%$ of cases (Morris-Brown 2005). Although the precise mechanisms by which alcohol exerts its carcinogenic effect have not been fully elucidated, the genotoxic effect of acetaldehyde as it is metabolised from ethanol has been strongly implicated 
BOX 2 Needle sharing and hepatoma

Susan at 45 had lived with chronic hepatitis B and C for many years, suffering the toll of what now seemed a brief phase of needle sharing in her late teens. She had had periods of treatment with interferon, liked to take ginseng herself, but knew that her liver function tests were abnormal with a cirrhotic process occurring. As more bruising occurred and ascites developed, imaging revealed a multifocal hepatocellular cancer, not deemed suitable for surgery. Treatment with sorafenib helped for a few months, but Susan felt very sad, alone, fatigued and nauseated. She wondered if further treatment was worthwhile. She had lost a lot of weight, yet her swollen belly caused discomfort and early jaundice was again apparent in her sclera. Acknowledging that she felt depressed, she asked to stop treatment so that she could die in peace. Psychotherapeutic support focused on the narrative of Susan's life, highlighting what she had accomplished and affirming the meaningful relationships in her life.

(Yokoyama 2005; Poschl 2004). There is also moderate evidence to suggest that alcohol serves as a solvent for other carcinogens (Boffetta 2006), which is particularly significant as the habits of both smoking and drinking are often combined.

Marijuana use has been linked to lung cancer in a manner similar to smoking, although studies are often methodologically confounded and results are contradictory (Hashibea 2005). Needle sharing in intravenous substance misuse leads to hepatitis infections that are strongly associated with the subsequent development of hepatocellular cancer (Lok 2009) (Box 2).

\section{What the literature tells us}

In view of the above, if there is a role for behavioural medicine to play in decreasing the burden of disease attributable to cancer, it is these modifiable lifestyle factors that should be addressed rather than the fixed nature of personality as whole.

\section{Stress, life events and risk of cancer development}

The notion that stress might be a cause of cancer is prevalent in many societies (Chida 2008; Johansen 2012). However, many of the studies that support this belief are weakened by methodological errors such as the retrospective attribution of a stressor as causal after the cancer has been diagnosed, or the lack of control for confounding lifestyle factors such as smoking, alcohol, obesity and exercise. (Dalton 2002a). Better studies have been based on the Danish Cancer Registry, established nationwide in 1943, and the Danish personal identification number, established in 1968, which permits linkage to clinical databases where lifestyle factors are recorded (Thygesen 2011).

Studies that have made use of these Danish data and looked for a link with cancer causation include 8042 parents who had lost a child (Li 2002) and 11231 parents whose child was diagnosed with cancer (Johansen 1997). Neither study found an increased risk of cancer in these parents, in keeping with Ewertz's classic bereavement study in 1986. These studies contrast, for example, with the findings of a large cohort of bereaved Israelis after the Yom Kippur War (Levav 2000), but the latter study carries a potential risk of selection bias compared with studies in which the samples were drawn from administrative registries, where the information on exposure was collected independently of any scientific hypotheses.

The US-based Nurses' Health Study of 69886 women examined the stress of providing informal care to relatives in one large subgroup (Kroenke 2004) and the presence of job stress in another (Schernhammer 2004): neither study found any increase in the occurrence of breast cancer in these women. A meta-analysis of 5700 incident cancer events in 116056 European men and women similarly found no association between self-reported 'job strain' at baseline and risk of cancer after 12 years (Heikkilä 2013).

Another type of stressor could be the diagnosis of mental illness. The Danes again examined all admissions to psychiatric wards since 1969, and from a cohort of 89491 such patients with major depression found no increased risk of cancer once smoking and alcohol were controlled for (Dalton 2002b). The diagnosis of schizophrenia as a stressor was examined in both patients and their parents, without any evidence of increased cancer risk (Dalton 2004, 2005).

Such Danish data are nationwide and population-based, with extensive follow-up over long periods. The results appear relatively robust and provide empirical evidence refuting the usual assumption that stress causes cancer. Clinicians with knowledge of this are empowered to provide substantial relief to patients who otherwise jump to an unwarranted retrospective attribution of their cancer to a recent and coincidental life event.

\section{Social support and outcome}

Early epidemiological studies indicated that social isolation was as powerful a cause of mortality in the general population as were smoking and high cholesterol (Goodwin 1987; Lai 1999). More recent examination of 734889 cancer patients in 
the Surveillance, Epidemiology and End Results (SEER) Medicare database (2004-2008) in the USA revealed that married patients were $20 \%$ less likely than unmarried to die of their cancer (after adjusting for demographics, stage and treatment: $\mathrm{HR}=0.80,95 \%$ CI 0.79-0.81, $P<0.001$ ) (Aizer 2013). For the ten leading cancers that result in death, married patients were less likely to present with metastatic disease and more likely to receive definitive anti-cancer therapy. The benefit associated with marriage was greater for men than women, but remained significant for women across all of the ten cancers. Being single, separated, widowed or divorced identifies a demographic that places people at risk of social isolation; identification and referral of individuals with this characteristic to psycho-oncology services may be warranted.

\section{Treatment adherence}

Social support has also been demonstrated to improve adherence to medical treatment. (DiMatteo 2004a). Although non-adherence to recommended anti-cancer therapies is associated with increased mortality among patients with cancer (Hershman 2011), it is important to consider that non-adherence may be an informed rational decision, based on experiences of toxicity or perceived benefit (or lack thereof). Of paramount importance therefore is the provision of satisfactory explanations of treatment options and joint decision-making informed by an understanding of the patient's attitudes and health beliefs, all of which can mediate better treatment adherence and outcome (Martin 2005).

\section{Group therapy and support groups}

Group therapy is a well-established support model for cancer services. When patients come together to share distress and grief with others who have experienced a similar predicament, adaptive healing with improved coping can be promoted. Group therapy has been shown to both prevent and ameliorate clinical depression and can promote adherence to anti-cancer therapy (Kissane 2007). Much hope was held that cancer support groups would improve survival (Spiegel 1989), yet careful replication studies involving women with advanced breast cancer, powered to detect a 15\% difference in survival (Goodwin 2001), have failed to show this (Goodwin 2001; Kissane 2007; Spiegel 2007). A ceiling effect may have resulted from the inclusion of married women, rather than targeting individuals at risk because of poor social support, clinical depression and unmarried status (Kissane 2013). Group leadership is vital to retaining the socially alienated in cancer support groups and creating an inclusive, cohesive group environment. Effective group facilitation is an expert clinical skill, necessitating staffing ratios adequate to the delivery of such services.

The development of interventions to help the leaders of community-based cancer support groups has been a welcome step forward (Zordan 2012). The interventions assessed - a group leaders' website and discussion forum, a DVD and group therapy leadership manual, and a 2-day evidencebased workshop - illustrate the sort of package needed to improve the quality of cancer support groups. A considerable training agenda exists here in many countries.

\section{Psychosocial factors in cancer progression and mortality}

Although the jury is still out regarding the role of behavioural factors in the aetiology of cancer, the evidence in favour of their effect on tumour progression is increasingly persuasive. Behavioural factors have been shown to contribute to the regulation of gene expression, immune response and the inflammatory process, highlighting the potential impact of mental state on disease progression (Constanzo 2011). Equally, the inflammatory process secondary to tumour growth has been linked to the pathogenesis of depression and cancer-related fatigue (Musselman 2001; Jehn 2006).

\section{Depression}

Depressive disorder is common among patients with cancer, yet not well recognised by busy clinicians when tears, grief and distress are normal components of the experience of diagnosis and disease progression. Screening for depression or distress can increase recognition of psychiatric disorder (Mitchell 2007). For example, when routine computerised out-patient screening for depression was introduced at a cancer centre in a randomised controlled trial, targeted psychosocial interventions resulted in a significant reduction in depression 6 months later (McLachlan 2001). Untreated clinical depression is strongly associated with poor adherence to anti-cancer treatments (DiMatteo 2000) and shorter survival, with mortality rates in meta-analyses increased by 19\% (Satin 2009) and 39\% (Pinquart 2010), depending on the studies selected.

At the primary care level, a large multi-site randomised controlled trial revealed reduced cancer mortality from screening for and treatment of depression (Gallo 2007). Among patients being treated for metastatic lung cancer, those who 
BOX 3 Is it grief or depression?

Mary had been shocked at her diagnosis of advanced pancreatic cancer. She was only 55 and, although one of her children had married, no grandchildren had been born. She cried freely when her oncologist suggested that her prognosis was guarded. Her fatigue had been pronounced for weeks; her sadness steadily deepened and spoilt most days. She wondered what was the point of life. Her oncologist reassured her that her distress was comprehensible: 'Chemotherapy is important to contain disease growth. It often causes fatigue due to mild anaemia, but Mary, you will learn to cope'. As Mary struggled on, poor concentration, reduced interest and poor sleep continued to spoil her quality of life. For a time she thought, 'I must keep trying for my family'. But her depressed mood steadily worsened until she became suicidal. Then psychiatric help was sought. Mary was treated with mirtazapine, chosen as an antidepressant to stimulate her appetite and help her sleep, while supportive psychotherapy employed activity scheduling and re-engagement with her family.

received early palliative care had longer survival and more effective symptom management, including reduced depression, than those receiving standard treatment (Temel 2010). There is no doubt that both the recognition and treatment of depression are vital (Box 3).

\section{Socioeconomic disadvantage}

The other major circumstance associated with shorter survival in people with cancer is socioeconomic disadvantage or social disparity. This is the case in countries both with (Dalton 2007; Gentil-Brevet 2008) and without universal access to healthcare (Jha 2006; Albano 2007). The health literacy of any cultural group may be central to the factors that influence their access to screening and early detection, but the complex interrelationships between the various contributory factors make understanding this difficult. Populationbased data-sets measure socioeconomic status inadequately, but there can be no doubt from the evidence base that disparities exist. Policy change is needed to address educational, occupational and income-related inequalities, but also to influence housing, exposure to carcinogens and promotion of a healthy lifestyle.

\section{Clinical perspectives}

Both the prevalence of depressive disorders and the consequences of untreated depression highlight the importance of its recognition and treatment in the comprehensive care of patients with cancer. Identifying those at risk of poorer outcomes - the unmarried, socially isolated and socioeconomically deprived - is also crucial to optimise care delivery. Poor lifestyle choices may lead to shame and stigma when cancer does occur, but much can be done to reassure those inclined to attribute their cancer to stress, life events or personality.

\section{Conclusions}

Cancer competes with cardiac disease as a leading cause of death in many societies. Psycho-oncology seeks to reduce distress, depression and suffering among people with cancer and their families. Knowledge of risk factors related to the incidence and progression of cancer will help the clinician to provide appropriate guidance about issues that commonly remain a source of confusion in society.

\section{References}

Abbey C, Thompson SBN, Hickish T, et al (2015) A meta-analysis of prevalence rates and moderating factors for cancer-related posttraumatic stress disorder. Psycho-Oncology, 24: 371-81.

Aizer AA, Chen MH, McCarthy E, et al (2013) Marital status and survival in patients with cancer. Journal of Clinical Oncology, 31: 3869-76.

Albano JD, Ward E, Jemal A, et al (2007) Cancer mortality in the United States by education level and race. Journal of National Cancer Institute, 99: 1384-94

Boffetta P, Hashibe M (2006) Alcohol and cancer. Lancet Oncology, 7: 149-56.

Burke BL, Arkowitz H, Menchola M (2003) The efficacy of motivational interviewing: a meta-analysis of controlled clinical trials. Journal of Consulting and Clinical Psychology, 71: 843-61.

Burkhalter JE, Springer CM, Chhabra R, et al (2005) Tobacco use and readiness to quit smoking in low-income HIV-infected persons. Nicotine \& Tobacco Research, 7: 511-22.

Calle EE, Kaaks R (2004) Overweight, obesity and cancer: epidemiological evidence and proposed mechanisms. Nature Reviews Cancer, 4: 579-91.

Carroll KK (1998) Obesity as a risk factor for certain types of cancer. Lipids, 33: 1055-9.

Changrani J, Gany F (2005) Paan and gutka in the United States: an emerging threat. Journal of Immigrant Health, 7: 103-8.

Chida Y, Hamer M, Wardle J, et al (2008) Do stress-related psychosocial factors contribute to cancer incidence and survival? Nature Reviews Clinical Oncology, 5: 466-75

Constanzo ES, Sood AK, Lutgendorf SK (2011) Biobehavioral influences on cancer progression. Immunology and Allergy Clinics of North America, 31: 109-32.

Craft LL, Van Iterson EH, Helenowski IB, et al (2011) Exercise effects on depressive symptoms in cancer survivors: a systematic review and meta-analysis. Cancer Epidemiology, Biomarkers \& Prevention, 21: 3-19.

Critchley JA, Unal B (2003) Health effects associated with smokeless tobacco: a systematic review. Thorax, 58: 435-43.

Dalton SO, Boesen EH, Ross L, et al (2002a) Mind and cancer: do psychological factors cause cancer? European Journal of Cancer, 38: 1313-23.

Dalton SO, Mellemkjaer L, Olsen JH, et al (2002b) Depression and cancer risk: a register-based study of patients hospitalized with affective disorders, Denmark, 1969-1993. American Journal of Epidemiology, 155: 1088-95.

Dalton SO, Munk Laursen T, Mellemkjaer L, et al (2004) Risk for cancer in parents of patients with schizophrenia. American Journal of Psychiatry, 161: 903-8. 
Dalton SO, Mellemkjaer L, Thomassen L, et al (2005) Risk of cancer in a cohort of patients hospitalized with schizophrenia in Denmark, 19691993. Schizophrenia Research, 75: 315-24.

Dalton SO, Ross L, During M, et al (2007) Influence of economic factors on survival after breast cancer: a nationwide cohort study of women diagnosed with breast cancer in Denmark 1983-1999. International Journal of Cancer, 121: 2524-31.

Derogatis L, Morrow G, Fetting J, et al (1983) The prevalence of psychiatric disorders among cancer patients. JAMA, 249: 751-7.

DiMatteo MR, Lepper HS, Croghan TW (2000) Depression as a risk factor for noncompliance with medical treatment: meta-analysis of the effects of anxiety and depression on patient adherence. Archives of Internal Medicine, 160: 2101-7.

DiMatteo MR (2004a) Social support and patient adherence to medical treatment: a meta-analysis. Health Psychology, 23: 207-18.

DiMatteo MR (2004b) Variations in patients' adherence to medical recommendations: a quantitative review of 50 years of research. Medical Care, 42: 200-9.

Eisenberg MJ, Filion KB, Yavin D, et al (2008) Pharmacotherapies for smoking cessation: a meta-analysis of randomized controlled trials. Canadian Medical Association Journal, 179: 135-44.

Ewertz M (1986) Bereavement and breast cancer. Cancer, 53: 701-3.

Freund M, Campbell E, Paul C, et al (2009) Increasing smoking cessation care provision in hospitals: a meta-analysis of intervention effect. Nicotine \& Tobacco Research, 11: 650-62.

Friedenreich CM, Orenstein MR (2002) Physical activity and cancer prevention: etiologic evidence and biological mechanisms. Journal of Nutrition, 132 (suppl 11): 3456s-64s.

Gallo JJ, Bogner HR, Morales KH, et al (2007) The effect of a primary care practice-based depression intervention on mortality in older adults: a randomized trial. Annals of Internal Medicine, 146: 689-98.

Gentil-Brevet J, Colonna M, Danzon A, et al (2008) The influence of socioeconomic and surveillance characteristics on breast cancer survival: a French population-based study. British Journal of Cancer, 98: 217-24.

Goodwin JS, Hunt WC, Key CR, et al (1987) The effect of marital status on stage, treatment and survival of cancer patients. JAMA, 258: 3125-30.

Goodwin PJ, Leszcz M, Ennis M, et al (2001) The effect of group psychosocial support on survival in metastatic breast cancer. New England Journal of Medicine, 345: 1719-26.

Grossarth-Maticek R, Eysenck HJ, Vetter H (1988) Personality type, smoking habits and their interaction as predictors of cancer and coronary heart disease. Personality and Individual Differences, 9: 479-99.

Haroon E, Raison CL, Miller AH (2012) Psychoneuroimmunology meets neuropsychopharmacology: translational implications of the impact of inflammation on behavior. Neuropsychopharmacology, 37: 137-62.

Hashibea M, Straifa K, Tashkin DP, et al (2005) Epidemiologic review of marijuana use and cancer risk. Alcohol, 35: 265-75

Heikkilä K, Nyberg ST, Theorell T, et al (2013) Work stress and risk of cancer: meta-analysis of 5700 incident cancer events in 116,000 European men and women. BMJ, 346: 1165

Hershman DL, Shao T, Kushi LH, et al (2011) Early discontinuation and non-adherence to adjuvant hormonal therapy are associated with increased mortality in women with breast cancer. Breast Cancer Research Treatment, 126: 529-37.

Javed F, Chotai M, Mehmood A, et al (2010) Oral mucosal disorders associated with habitual gutka usage: a review. Oral Surgery, Oral Medicine, Oral Pathology, Oral Radiology, and Endodontology, 109: 857-64.

Jehn CF, Kuehnhardt D, Bartholomae A, et al (2006) Biomarkers of depression in cancer patients. Cancer, 107: 2723-9.

Jha P, Peto R, Zatonski W, et al (2006) Social inequalities in male mortality, and in male mortality from smoking: indirect estimation from national death rates in England and Wales, Poland and North America. Lancet, 368: 367-70.
Johansen C, Olsen JH (1997) Psychological stress, cancer incidence and mortality from non-malignant diseases. British Journal of Cancer, 75 : $144-8$.

Johansen C (2012) Mind as a risk factor for cancer: some comments. Psycho-Oncology, 21: 922-6.

Jokela M, Batty GD, Hinta T, et al (2014) Is personality associated with cancer incidence and mortality? An individual-participant meta-analysis of 2156 incident cancer cases among 42,843 men and women. British Journal of Cancer, 110: 1820-4.

Kissane DW, Grabsch B, Clarke DM, et al (2007) Supportive-expressive group therapy for women with metastatic breast cancer: survival and psychosocial outcome from a randomized controlled trial. PsychoOncology, 16: 227-86.

Kissane DW (2013) Marriage is as protective as chemotherapy in cancer care. Journal of Clinical Oncology, 31: 3852-3.

Kroenke CH, Hankinson SE, Schernhammer ES, et al (2004) Caregiving stress, endogenous sex steroid hormone levels, and breast cancer incidence. American Journal of Epidemiology, 159: 1019-27.

Kruk J, Czerniak U (2013) Physical activity and its relation to cancer risk: updating the evidence. Asian Pacific Journal of Cancer Prevention, 14: 3993-4003.

Lai H, Lai S, Krongrad A, et al (1999) The effect of marital status on survival in late-stage cancer patients: an analysis based on surveillance, epidemiology, and end results (SEER) data, in the United States. International Journal of Behavioral Medicine, 6. 150-76.

Lee I (2003) Physical activity, exercise, and cancer: prevention to treatment. Medicine and Science in Sports and Medicine, 35: 1823-7.

Levav I, Kohn R, Iscovich J, et al (2000) Cancer incidence and survival following bereavement. American Journal of Public Health, 90: 1601-7.

Li D, Yeung SCJ, Hassan MM, et al (2009) Anti-diabetic therapies affect risk of pancreatic cancer. Gastroenterology, 137: 482-8.

Li J, Johansen C, Hansen D, et al (2002) Cancer incidence in parents who lost a child: a nationwide study in Denmark. Cancer, 95: 2237-42.

Lok AS, Seeff LB, Morgan TR, et al (2009) Incidence of hepatocellular carcinoma and associated risk factors in hepatitis C-related advanced liver disease. Gastroenterology, 136: 138-48.

Luppino FS, de Wit LM, Bouvy PF, et al (2010) Overweight, obesity and depression. Archives of General Psychiatry, 67: 220-9.

Martin LR, Williams SL, Haskard KB, et al (2005) The challenge of patient adherence. Therapeutics and Clinical Risk Management, 1: 189-99.

Maziak W (2013) The waterpipe: an emerging global risk for cancer Cancer Epidemiology, 37: 1-4

McBride CM, Ostroff JS (2003) Teachable moments for promoting smoking cessation: the context of cancer care and survivorship. Cancer Control, 10: 325-33

McLachlan SA, Allenby A, Matthews J, et al (2001) Randomized trial of coordinated psychosocial interventions based on patient selfassessments versus standard care to improve psychosocial functioning of patients with cancer. Journal of Clinical Oncology, 19: 4117-25.

Mehnert A, Koch U, Schulz H, et al (2012a) Prevalence of mental disorders, psychosocial distress and need for psychosocial support in cancer patients: study protocol of an epidemiological multi-center study. BMC Psychiatry, 12: 70

Mehnert A, Faller H, Härter M, et al (2012b) Prevalence of mental disorders and psychosocial distress in cancer patients: an epidemiological study. Asia-Pacific Journal of Clinical Oncology: Oral Abstracts, 8 (suppl S3): 115-217.

Mitchell AJ (2007) Pooled results from 38 analyses of the accuracy of distress thermometer and other ultra-short methods of detecting cancerrelated mood disorder. Journal of Clinical Oncology, 25: 4670-81.

Mitchell A, Chan M, Bhatti $H$, et al (2011) Prevalence of depression, anxiety, and adjustment disorder in oncological, haematological, and palliative-care settings: a meta-analysis of 94 interview-based studies. ancet Oncology $12 \cdot 160-74$ 
Morris-Brown L (2005) Epidemiology of alcohol-associated cancers. Alcohol, 35: 161-8.

Musselman DL, Miller AH, Porter MR, et al (2001) Higher than normal plasma interleukin-6 concentrations in cancer patients with depression: preliminary findings. American Journal of Psychiatry, 158: 1252-7.

Nakaya N, Bidstrup PE, Saito-Nakaya K, et al (2010) Personality traits and cancer risk and survival based on Finnish and Swedish registry data. American Journal of Epidemiology, 172: 377-85.

Parsons A, Daley A (2010) Influence of smoking cessation after diagnosis of early stage lung cancer on prognosis: systematic review of observational studies with meta-analysis. BMJ, 340: b5569.

Pinquart M, Duberstein PR (2010) Depression and cancer mortality: a meta-analysis. Psychological Medicine, 40: 1797-810.

Poschl G, Seitz HK (2004) Alcohol and cancer. Alcohol \& Alcoholism, 39: 155-65

Redinger RN (2007) Obesity: pathophysiology and clinical manifestations. Gastroenterology \& Hepatology, 3: 856-63.

Satin JR, Linden W, Phillips MJ (2009) Depression as a predictor of disease progression and mortality in cancer patients. Cancer, 115: 5349-61.

Schapiro IR, Ross-Petersen L, Sælan H, et al (2001) Extroversion and neuroticism and the associated risk of cancer: a Danish cohort study. American Journal of Epidemiology, 153: 757-63.

Schernhammer ES, Hankinsin SE, Rosner B, et al (2004) Job stress and breast cancer risk: the Nurses' Health Study. American Journal of Epidemiology, 160: 1079-86.

Shaffer JW, Graves PL, Swank RT, et al (1987) Clustering of personality traits on youth and the subsequent development of cancer among physicians. Journal of Behavioral Medicine, 10: 441-7.

Shishani K, Roll J, Armstrong M (2012) Hookah use: going down in smoke. Journal of Addictions Nursing, 23: 112-5.

Speck RM, Courneya KS, Masse LC, et al (2010) An update of controlled physical activity trials in cancer survivors: a systematic review and metaanalysis. Journal of Cancer Survivorship, 4: 87-100.
Spiegel D, Kraemer H, Bloom J, et al (1989) Effect of psychosocial treatment on survival of patients with metastatic breast cancer. Lancet, 334: 888-91.

Spiegel D, Butler L, Giese-Davis J, et al (2007) Effects of supportiveexpressive group therapy on survival of patients with metastatic breast cancer. Cancer, 110: 1130-8.

Temel JS, Greer JA, Muzikansky A, et al (2010) Early palliative care for patients with metastatic non-small-cell lung cancer. New England Journal of Medicine, 363: 733-42.

Temoshok L (1987) Personality, coping style, emotion and cancer: towards an integrative model. Cancer Surveys, 6: 545-67.

Thygesen LC, Ersboll AK (2011) Danish population-based registers for public health and health-related welfare research: introduction to the supplement. Scandinavian Journal of Public Health, 39: 8-10.

Vehling S, Koch U, Ladehoff N, et al (2012) Prevalence of affective and anxiety disorders in cancer: systematic literature review and metaanalysis [in German]. Psychotherapie, Psychosomatik, Medizinische Psychologie, 62: 249-58.

Wakefield M, Spittal M, Durkin S, et al (2011) Effects of mass media campaign exposure intensity and durability on quit attempts in a population-based cohort study. Health Education Research, 26 : 988-97.

Wolk A, Gridley G, Svensson M, et al (2001) A prospective study of obesity and cancer risk (Sweden). Cancer Causes and Control, 12: 13-21.

Yokoyama A, Omori T (2005) Genetic polymorphisms of alcohol and aldehyde dehydrogenases and risk for oesophageal and head and neck cancers. Alcohol, 35: 175-85.

Zordan RD, Butow PN, Kirsten L, et al (2012) The development of novel interventions to assist the leaders of cancer support groups. Supportive Care in Cancer, 20: 445-54.

Zuckerman M, Kuhlman DM (2000) Personality and risk-taking: common biosocial factors. Journal of Personality, 68: 999-1029.

\section{MCQs}

Select the single best option for each question stem

\section{Research shows that:}

a stress is a common cause of cancer

b major life events are associated with the development of cancer

c stress is not accepted as a cause of cancer

d increased rates of cancer follow distressing bereavement

e diagnosis of schizophrenia in a child can result in the development of cancer in the parents.

\section{As regards depression:}

a unrecognised or untreated depression is associated with shorter cancer survival

b depression in the mentally ill is a cause of cancer

c depression is unrelated to treatment adherence among the medically ill

$\mathrm{d}$ treatment of depression has no impact on cancer survival e group therapy has no impact on ameliorating depression among cancer patients.

3 In oncology and cancer care

a death anxiety is the basis of affective disorders in oncology

b somatoform disorders are common because patients become hypervigilant about bodily symptoms

c post-traumatic stress disorders are very common, given the trauma of the cancer diagnosis

$\mathrm{d}$ alcohol use disorders are uncommon

e premorbid mental disorders are more predictive of psychiatric disorders in patients with cancer than is the diagnosis of cancer itself.

\section{As regards smoking and cancer:}

a advising smokers to quit is a waste of time

b motivational counselling is very effective in stopping smoking c attention to smoking status while patients are in hospital is inconsequential

d combination pharmacotherapy and motivational counselling achieves incremental benefits in stopping smoking

e only smoking and not alcohol ingestion is linked to causing cancer.

5 Regarding impact on cancer:

a the stress of being married can increase risk for cancer

b marriage improves the cancer survival rates in men but not in women

c group support is trendy but is an unproven cancer therapy

$\mathrm{d}$ widowers do as well as married men in cancer survival outcomes

e social isolation is associated with higher mortality. 